\title{
Partial Resistance of Pepper to Bacterial Wilt Is Oligogenic and Stable Under Tropical Conditions
}

\author{
Denis Lafortune and Michel Béramis, INRA-URPV, Domaine Duclos, Prise d'eau, 97170 Petit Bourg, France; and \\ Anne-Marie Daubèze, Nathalie Boissot, and Alain Palloix, INRA-GAFL, BP 94, 84143 Montfavet Cedex, France
}

\begin{abstract}
Lafortune, D., Béramis, M., Daubèze, A.-M., Boissot, N., and Palloix, A. 2005. Partial resistance of pepper to bacterial wilt is oligogenic and stable under tropical conditions. Plant Dis. 89:501-506.

Genetic analysis of resistance of pepper to bacterial wilt was performed in the doubled haploid progeny from a cross between a resistant parental line PM 687 and a susceptible cultivar Yolo Wonder. After artificial inoculation with a local isolate of Ralstonia solanacearum, the progeny consisting of 90 lines was transplanted into a naturally infested field in Guadeloupe, Lesser Antilles. The 2 years of experimentation resulted in repeatable results, with a high heritability of the resistance, attesting the reliability of the evaluation procedure and the stability of the resistance over years. Two to five genes with additive effects were estimated to control the resistance, indicating an oligogenic control as observed in tomato sources of resistance. Relationships with resistance to other soilborne or tropical diseases were examined. Susceptibility to Tobacco mosaic virus (TMV) and to nematodes (Meloidogyne spp.) were significantly linked with resistance to bacterial wilt, whereas neither resistance to Phytophthora capsici nor to Leveillula taurica were linked. The similarity of the genetics of resistance to bacterial wilt in pepper and tomato and linkage with TMV resistance locus warrant the comparative mapping of the resistance quantitative trait loci in the genomes of the two species.
\end{abstract}

Additional keywords: Capsicum annuum, doubled haploid lines, field resistance, genetic linkage

Bacterial wilt due to Ralstonia solanacearum is a widespread and devastating disease of many crops, ornamentals, and weeds in the tropics and subtropics all over the world (13). Crop losses are particularly significant in the solanaceous vegetables including eggplant, pepper, potato, and tomato. Yoon et al. (37) sent a survey to 55 countries of the intertropical belt; $34 \%$ rated $R$. solanacearum as a major problem in pepper cultivation with high to very high incidence, ranking bacterial wilt as the fourth major pepper disease below virus complexes, Phytophthora root rot, and anthracnose. Bacterial wilt is a common disease in the Caribbean $(28,29)$, Latin America (30), West Africa, and Southeast Asia (37), where pepper is confronted by the different biovars and races of the bacterium. More recently, $R$. solanacearum was reported in temperate climates of Northern and Western Europe (35).

$R$. solanacearum has been classified into races and biovars. Initially, five races were identified based on host range and six biovars based on biochemical properties

Corresponding author: D. Lafortune

E-mail: denis.lafortune@antilles.inra.fr

Accepted for publication 8 January 2005.

DOI: 10.1094/PD-89-0501

(C) 2005 The American Phytopathological Society
$(12,13,28)$. There are no strict relationships between races and biovars; for example, race 1 characterized by a large host range (at least seven host families) includes strains from biovars 1, 3, and 4. More recently, phylogenetic analysis based on molecular approaches indicated that $R$. solanacearum may be regarded as a species complex containing four different phylotypes related to the geographical origin of the strains (9). Relationships with races and biovars are not strict; for example, the phylotype II representative of the American strains includes strains from races 1, 2 (the Musaceae strains), and 3 (the potato and tomato strains adapted to temperate climates), and strains from biovars 1,2 , and $2 \mathrm{~T}$.

Many resistant pepper accessions have been described from local genetic resources, mainly in small-fruited and pungent pepper types $(21,25)$. In every accession, resistance was quantitatively expressed, but genetic analyses have never been reported. In potato, tomato, and tobacco, resistance was shown to be quantitatively expressed and under the control of multiple genes, except for the case of major resistance genes that have been reported in some tobacco accessions $(3,10,24,32,34)$. Race-cultivar specificity was suspected because the resistant accessions displayed different resistance levels in different geographic locations. However, when challenged with known strains of the bacterium rather than heterogeneous popu- lations, most resistant accessions showed a stable resistance compared with the different races or biovars tested, particularly the highly variable biovar 1. Quantitative differences were correlated with strain aggressiveness rather than with virulence $(18,30,34)$. Environmental factors including air and soil temperature, humidity, and nematode infections strongly affect expression of resistance and may explain most of the differences between locations (13). Only one study clearly demonstrated the specificity of resistance: the tomato cultivar Hawai 7996, which displayed a large-spectrum resistance to several strains from biovars 1 and 3 , was submitted to genetic mapping of the resistance quantitative trait loci (QTLs). Two QTLs on chromosome 6 and one on chromosome 8 were shown to be involved in resistance to the different strains in different locations, but one QTL on chromosome 12 having a major effect was specifically detected with the Taiwanese strain Pss4 of biovar 3 $(19,36)$. This genetic dissection of resistance confirmed previous results that largespectrum resistance to pathogens can result from the combination of strain-specific QTLs (17). This information is useful for breeding cultivars adapted to different growing regions.

In pepper, one particular accession (PM 687) displayed a stable resistance to bacterial wilt in different locations and has been used as a progenitor for breeding programs (2). Introgression of the bacterial wilt resistance from this small-fruited pepper into large-fruited cultivars could benefit from knowledge of genetic control, of linkage with other traits, and of QTL mapping that will provide molecular markers for marker-assisted selection. Accession PM 687 possesses resistance to other soilborne or tropical pathogens, namely to Meloidogyne spp., Phytophthora capsici, powdery mildew, and Potato virus $Y$ (PVY) $(5,6,8,27)$. In order to analyze the genetics and the linkage relationships between those resistance traits, a doubled haploid progeny was obtained from the F1 hybrid between PM 687 and a large-fruited pepper that was susceptible to all the above pathogens but resistant to Tobacco mosaic virus (TMV). Doubled haploid progenies, which can be reproduced by selfing, offer the opportunity to integrate the genetic analysis of many traits and to map continuously new markers in a single progeny $(15,27)$. 
In this work, we used the F1-derived doubled haploid progeny to analyze the resistance of the pepper accession PM 687 to bacterial wilt caused by $R$. solanacearum strains from the French Lesser Antilles (Guadeloupe), its stability over years, and the genetic control of this resistant accession. Relationships with other resisin the same progeny were also examined as a prerequisite to genetic mapping and to introgression of bacterial wilt resistance into large-fruited (bell) pepper cultivars.

\section{MATERIALS AND METHODS}

Plant material, bacterial strain, and artificial inoculation methods. PM 687 is a Capsicum annuum inbred line obtained from the USDA PI 322719 accession. It produces small pungent fruits. Yolo Wonder is a bell pepper inbred line from the University of California (USA). A progeny of 90 doubled haploid (DH) lines was obtained from the F1 hybrid through in vitro androgenesis.

Before transplanting the progeny into a naturally infested field, a preinoculation was performed to synchronize primary infection and to avoid escape from natural infection. The $R$. solanacearum strain was tance traits that were previously analyzed

isolated in 1990 from pepper in a research field of INRA-URPV in Guadeloupe, Lesser Antilles. It belongs to biovar 1, race 1 according to the nomenclature of Hayward (12) and to phylotype II according to Fegan and Prior (9). In addition to its host origin (pepper), this strain was chosen because it is representative of the phylotype II, race 1 , biovar 1 occurring commonly in Guadeloupe as well as elsewhere in the Caribbean and Americas. It was stored and cultivated on Kelman's medium as described by Prior et al. (29). Inoculum consisted of an aqueous suspension $\left(10^{7}\right.$ $\mathrm{CFU} / \mathrm{ml}$ ) of a 24 -h culture grown at $30^{\circ} \mathrm{C}$. Inoculation was performed by pouring 2 $\mathrm{ml}$ of the bacterial suspension into each individual 50-ml plant pot. Plants grown in a shaded glasshouse were inoculated at the four-leaf stage. They were transplanted in the infested plots 4 to 5 days after inoculation.

Field experiments for bacterial wilt assessment. Experiments were conducted in the same field used to obtain the $R$. solanacearum isolate from May to October 1999 (year 1) and from March to September 2001 (year 2) under sprinkler irrigation. This time period includes the hot and rainy season that is highly favorable to

\section{Year 1}

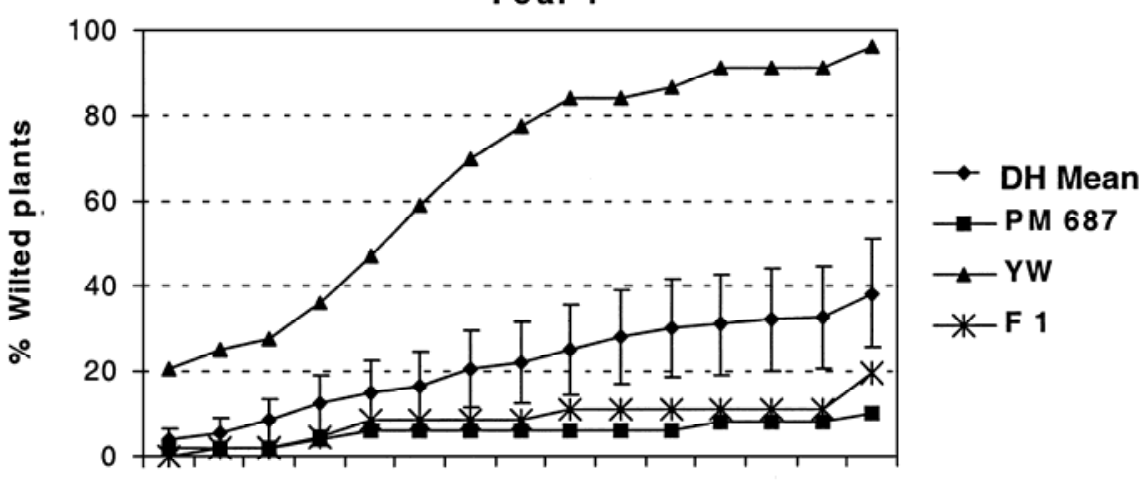

Year 2

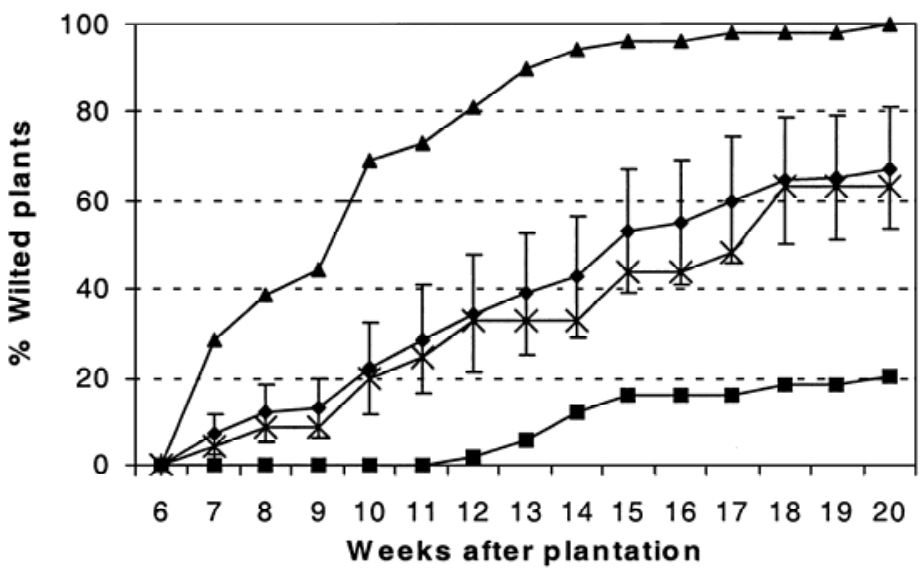

Fig. 1. Time course of bacterial wilt incidence for different genotypes of peppers during the 2 years of experimentation in Guadeloupe. Mean percentage of wilted plants is indicated for the resistant parental line (PM 687), the susceptible parental line Yolo Wonder (YW), their F1 hybrid (F1), and the doubled haploid population (DH mean). Vertical bars are standard deviation of the population. bacterial wilt. Total rainfall during the 6month experiment was similar for the 2 years, with $1,452 \mathrm{~mm}$ in year 1 and 1,455 $\mathrm{mm}$ in year 2 . Temperature was slightly lower during the year 1 experiment, with an average temperature of $25.0^{\circ} \mathrm{C}$ and a maximum of $32.6^{\circ} \mathrm{C}$, than in the year 2 experiment, when temperature averaged $26.6^{\circ} \mathrm{C}$ and reached a maximum of $34.8^{\circ} \mathrm{C}$. Inoculum density in this naturally infested research field was maintained by repeated cultivation of susceptible tomato, eggplant, and pepper every year since 1990. The naturally occurring $R$. solanacearum population included a mixture of biovars 1 and $3(4,28)$. Five blocks of 10 plants per genotype were arranged in a randomized complete block design. During 20 weeks, plants were checked weekly for wilting in the morning, and the number of wilted plants per block was noted.

Data analysis. For each genotype, the time course of the frequency of wilted plants was established for every block, and the area under the disease progress curve (AUDPC value) was computed with the formula: AUDPC $=\sum_{i=1}^{n}\left[\left(p_{i}+p_{i+1}\right) / 2\right]\left(t_{i+1}\right.$ $\left.-t_{i}\right)$ where $p_{i}=$ proportion of wilted plant at the date $t_{i}\left(t_{i}\right.$ expressed in weeks). A first analysis of variance of the AUDPC parameter was performed according to the model $Y=\mu+g_{i}+a_{j}+\left(g_{i} * a_{j}\right)+e_{i j}$, where $\mu=$ population mean, $g_{i}=$ genotype (HD lines) effect, $a_{j}=$ year effect, and $e_{i j}=$ residual. A second analysis of variance of AUDPC was performed for the 2 years separately according to the model $Y=\mu+$ $g_{i}+b_{j}+e_{i j}$, where $b_{j}=$ block effect. In this analysis, only DH lines with a complete data set (AUDPC values for the five blocks) were considered (81 $\mathrm{DH}$ lines in year 1 and $82 \mathrm{DH}$ lines in year 2). Because of the homozygosity of DH lines, genotypic variance was equal to additive variance (in the absence of epistatic effects), and narrow sense heritability $\left(h^{2}{ }_{n}\right)$ values were computed using the formula $h_{n}^{2}=$ $\sigma_{A}^{2} /\left(\sigma_{A}^{2}+n \sigma_{E}^{2}\right)$, where $\sigma_{A}^{2}=$ genotypic variance, $\sigma_{E}^{2}=$ environmental variance (including block and error effects), and $n$ is the number of repeats (blocks). The number of segregating genes in DH populations was estimated by the ratio between the square of the mid-deviation between the parents $\left(\mathrm{P}_{1}\right.$ and $\left.\mathrm{P}_{2}\right)$ and the additive variance: $k_{1}=\left[\left(P_{1}-P_{2}\right) / 2\right]^{2} / \sigma_{A}^{2}(20)$ or by dividing the square of the mid-deviation between the two extreme DH lines $\left(L_{\min }\right.$ and $\left.L_{\max }\right)$ by the additive variance: $k_{2}=$ $\left[\left(L_{\max }-L_{\min }\right) / 2\right]^{2} / \sigma_{A}^{2}(33)$.

To look for the relationships between resistance to bacterial wilt and resistance to other soilborne or tropical diseases, bacterial wilt resistance data were compared with data obtained on the same progeny and published elsewhere (5-8,27). PM 687 was characterized as resistant to Meloidogyne spp., Phytophthora root rot, powdery mildew caused by Leveillula taurica, and PVY. Yolo Wonder possesses the $L^{l}$ 
dominant allele for resistance to TMV. Previously, the doubled haploid lines were evaluated repeatedly for those traits, providing evidence for the monogenic inheritance and qualitative expression of resistance to root-knot nematodes $(7,8)$, TMV, and PVY $(6,27)$, and for the polygenic inheritance and quantitative expression of resistance to $P$. capsici (6) and L. taurica $(5,27)$. Considering the polygenic resistances, the Pearson correlation coefficients were computed between the mean AUDPC values (resistance to bacterial wilt) of the doubled haploid lines and the mean resistance values of the same lines for resistance to $P$. capsici and $L$. taurica. Independence with the monogenic resistances was tested by comparing the average AUDPC value for TMV (or PVY or nematode) resistant lines to the average value for the TMV (or PVY or nematode) susceptible lines (bilateral Student $t$ test for samples with different variances).

All the statistical analyses were conducted using the $\mathrm{R}$ software, version 1.7.1. (14), available from the Comprehensive R Archive Network (http://cran.r-project.org/).

\section{RESULTS}

Development of the epidemics and phenotype of the doubled haploid progeny. The time course of disease incidence for the 2 years is displayed in Figure 1 . Wilting was first observed between the third and the sixth week after transplanting in a few plants of the susceptible parent. Symptoms developed on the other plants and genotypes from the sixth up to the twentieth week. Plants displaying wilting symptoms generally died 2 to 3 weeks after symptoms first appeared. The epidemic of year 2 was more severe than that of year 1 , as evidenced by the rapid development of disease in the susceptible control Yolo Wonder and the higher percentages of wilted plants at the end of the year 2 experiment, for both the parental lines and the DH progeny, which reached an average of $38 \%$ wilted in year 1 and $67 \%$ wilted in year 2. Resistance of the PM 687 inbred line was quantitatively expressed with $10 \%$ (year 1) to $20 \%$ (year 2) wilted plants 20 weeks after transplanting, hence displaying a stable resistance under those conditions. The F1 hybrid was much more affected in year 2 than in year 1, displaying a low stability of resistance expression at the heterozygous state.

Table 1. Mean AUDPC values for bacterial wilt symptoms (and standard deviation) of the pepper parental lines (Yolo Wonder and PM 687), their F1 hybrid, and the doubled haploid (DH) population in two experiments

\begin{tabular}{lcc}
\hline & Year 1 & Year 2 \\
\hline Yolo Wonder & $9.56(0.83)$ & $9.56(2.06)$ \\
PM 687 & $0.81(1.31)$ & $0.95(0.77)$ \\
F1 hybrid & $1.19(2.02)$ & $3.96(2.91)$ \\
DH population & $3.02(2.48)$ & $4.64(2.74)$ \\
\hline
\end{tabular}

AUDPC values of the parental lines, F1 hybrid, and DH progeny (Table 1) were very similar between years for the parental lines but higher in year 2 for the F1 hybrid and the DH progeny. The phenotypic correlation between years for those lines was highly significant (Fig. 2).

For distribution analysis, doubled haploid lines were sorted into AUDPC classes with $n \leq$ mean AUDPC value of the line < $n+1$. The distribution of the doubled haploid progeny (Fig. 3) in AUDPC classes displayed a continuous distribution between the parents, with a tendency toward a multimodal distribution. No doubled haploid lines were significantly more resistant or more susceptible than the resistant or susceptible parent (Student $t$ test, $P=$ 0.05). A significant shift of the F1 hybrid from the resistant AUDPC-class 2 to the intermediate class 4 was noted between the years.

Genetic analysis of the resistance. Analysis of variance of the AUDPC values for the doubled haploid lines revealed a significant year effect and a significant interaction among years and genotypes. Hence, the 2 years were analyzed separately. Homogeneity of variance was observed between blocks (Bartlett test: $P=$ 0.08 for year 1 and 0.85 for year 2) but not between genotypes $(P=0.03)$ due to the high variance of intermediate lines and low variance of the extreme lines. However, the normality of residuals was observed for the 2 years (Shapiro-Wilk test: $P=0.07$ for year 1 and 0.67 for year 2). The analyses of variance for years 1 and 2 (Table 2) indicated that both the genotype and the block sources of variations were significant. The spatial pattern of symptomatic plants was not uniform in these experiments, despite the artificial inoculation of every plant preceding field planting. However, the narrow-sense heritabilities remained very high in both years $(0.86$ and 0.90; Table 3), indicating that genotypic effects were predominant in the experiment.

The number of genetic factors involved in the DH progeny segregation was estimated according to the methods of Mather and Jinks (20) and Snape et al. (33). The results in Table 3 indicated that three to five loci with additive alleles control the resistance in the year 1 experiment, and two to three loci with additive alleles are proposed to explain the segregation in the year 2 experiment.

Relationships between resistance to $R$. solanacearum and other traits. Among the 90 doubled haploid lines evaluated for bacterial wilt resistance, 50 lines were repeatedly evaluated in previous studies for quantitative resistance to $P$. capsici and to $L$. taurica, which cause Phytophthora root rot and powdery mildew, respectively. The correlation coefficients between resistance to bacterial wilt (AUDPC values from the 2 years) and the resistances to $P$. capsici and $L$. taurica were very weak (0.10 and -0.12), and none were significant at $P<0.05$. Independence with the qualitative and monogenic resistances to root-knot nematodes, PVY, and TMV was tested by comparing the AUDPC means of resistant versus susceptible doubled haploid lines (Table 4). AUDPC values were

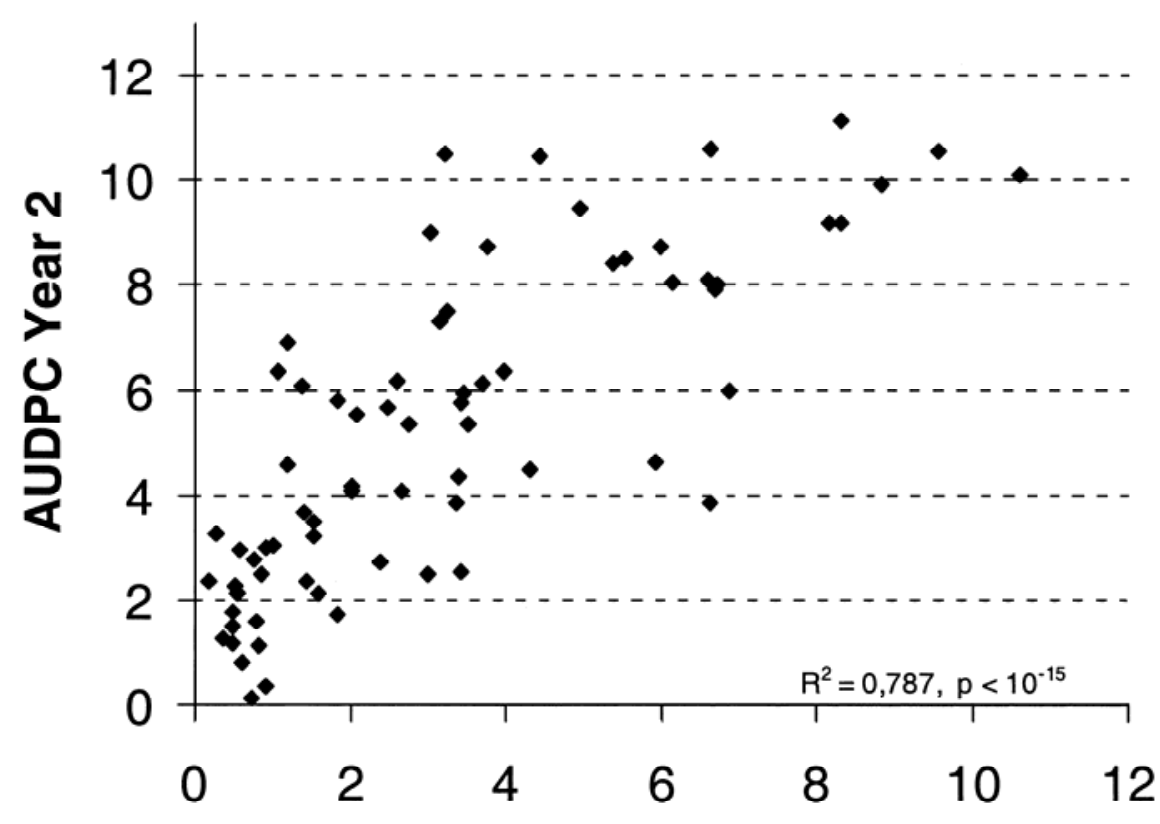

\section{AUDPC Year 1}

Fig. 2. Relationships between the AUDPC of bacterial wilt incidence values on the doubled haploid lines of pepper from the 2 years of experimentation in Guadeloupe. The correlation coefficient $\left(R^{2}\right)$ and significance $(P)$ are indicated. 
significantly different between nematode resistant and nematode susceptible lines $(P$ $=0.02$ ) and between TMV resistant and TMV susceptible lines $(P=0.001)$. TMV resistant lines were more susceptible to bacterial wilt than TMV susceptible lines, as expected from the parental alleles (Yolo Wonder is resistant and PM687 is susceptible to TMV). Nematode resistant lines were more susceptible to bacterial wilt than nematode susceptible lines, contrary to the expectations from parental alleles (PM 687 is resistant and Yolo Wonder is susceptible to nematodes).

\section{DISCUSSION}

This analysis of quantitative resistance to bacterial wilt caused by $R$. solanacea-
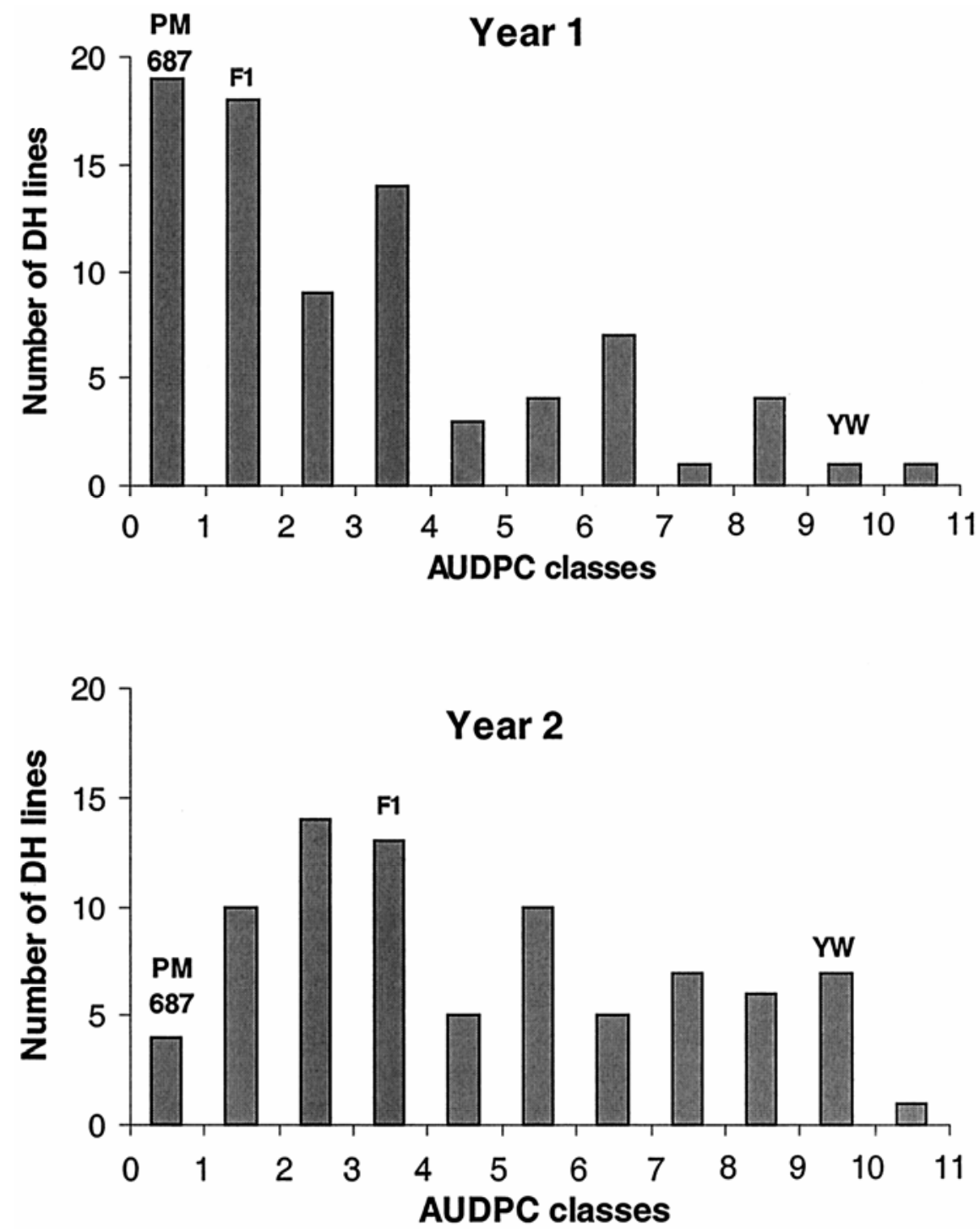

Fig. 3. Distribution of the doubled haploid (DH) population of pepper in AUDPC classes for resistance to bacterial wilt obtained from the 2 years of experimentation. The doubled haploid lines were sorted into AUDPC classes with $n \leq$ mean AUDPC value of the line $<n+1$. The class of the AUDPC mean value of the parental lines (PM 687 and Yolo Wonder) and the F1 hybrid are indicated.

Table 2. Analysis of variance of bacterial wilt symptom expression (AUDPC values) in the doubled haploid progeny of pepper for two experiments

\begin{tabular}{lrcrc}
\hline $\begin{array}{l}\text { Source of } \\
\text { variation }\end{array}$ & df & Mean square & $\boldsymbol{F}$ value & $\boldsymbol{P (}(\boldsymbol{F})$ \\
\hline Year 1 & & & & \\
Genotype & 80 & 32.99 & 8.60 & $<2.210^{-16}$ \\
Block & 4 & 80.81 & 21.05 & $2.010^{-15}$ \\
$\quad$ Residuals & 320 & 3.84 & & \\
Year 2 & & & & \\
Genotype & 81 & 46.21 & 12.27 & $<2.210^{-16}$ \\
Block & 4 & 71.50 & 18.99 & $4.810^{-14}$ \\
Residuals & 324 & 3.77 & & \\
\hline
\end{tabular}


lygenic traits. Previous analyses for the same progeny demonstrated correlations and linkage between quantitative resistance to powdery mildew and poor fruit set, or between resistance genes to nematodes $(5,7,27)$. A significant relationship was detected between susceptibility to bacterial wilt and resistance to TMV ( $L^{I}$ allele controlling hypersensitivity in Yolo Wonder) and resistance to nematodes ( $\mathrm{Me} 3$ and $M e 4$ genes from PM 687). In tomato, the major QTL for resistance to bacterial wilt on chromosome 6 is linked (in repulsion phase) with the Mi 1 gene for resistance to root-knot nematodes (34). The pepper line PM 687 has two genes for nematode resistance on chromosome 9 (7) that were anticipated to confer a selective advantage since root-knot nematodes are known to facilitate infection by $R$. solanacearum. However, our analysis showed that nematode resistant lines were more susceptible to bacterial wilt, and genetic linkage could not explain this relationship. The relationship between bacterial wilt resistance and TMV resistance (due to the $L^{l}$ allele from Yolo Wonder) suggested a linkage between the $L$ locus and one of the QTLs controlling bacterial wilt. The test was highly significant, indicating that the linkage should be tight or that the putative QTL had a strong effect. The $L$ locus was previously mapped on the pepper chromosome $\mathrm{P} 11$, and this genomic region corresponds to the upper part of tomato chromosome 12 (16), which bears a major QTL for resistance to bacterial wilt in tomato (36). Gene homologues of the tomato resistance genes Pto and Fen were also mapped in the pepper chromosome 11 $(16,26)$. This collinearity provides a hypothetic track for genetic mapping of the resistance to bacterial wilt in pepper.

The resistant and susceptible parental lines differed by the time course of wilting symptoms and the wilting percentage at different dates. The progeny displayed intermediate wilting progress curves. AUDPC, integrating both the kinetics and the level of symptom expression, provided the best quantitative descriptor for resistance/susceptibility phenotypes. Genetic analysis of the progeny suggested that the resistance of PM 687 to bacterial wilt is controlled by several genes. The tendency for a bimodal distribution of level of susceptibility and the estimated number of segregating factors (which varied from two to five) indicated that the genetic control is oligogenic. The intermediary resistance of the F1 hybrid indicated an additive rather than a dominant inheritance under the severe conditions for infection that occurred during this study. Methods for the estimation of the number of segregating factors (33) is subjected to three main hypotheses: (i) presence of the two extreme lines in the DH progeny, (ii) absence of linkage, and (iii) equivalence of gene effects. The first hypothesis can be accepted since the probability of presence of the extreme lines in a biallelic population of $90 \mathrm{DH}$ lines is $P>0.999$ for two loci and $P=0.963$ for 4.8 loci. The second hypothesis cannot be verified and has to be assumed. The third is generally not verified, and most available mapping data showed that quantitative resistance currently depends on the combination of a few loci with large-effect QTLs and several additional loci with minor-effect QTLs (17,22).

Genetics of resistance in pepper is very similar to that in tomato based on results from our study. One major plus two to five minor QTLs also were detected when mapping the resistance to bacterial wilt from tomato $(3,34)$. Comparing the resistant responses of tomato, pepper, and eggplant cultivars to the infection by $R$. solanacearum, Grimault and Prior (11) and Abdullah and Rahman (1) reported that all were subject to latent infection, but tomato and eggplant limited the invasion of vascular tissues by the bacteria. In peppers, the bacteria invaded the vascular tissues, but the plants displayed a high tolerance to bacterial invasion of the stem vascular system, resulting in very weak wilting symptoms of the tolerant genotypes. However, other studies devoted to distinct source of resistance reported a restriction of bacterial multiplication and active defense mechanisms in resistant peppers (31), as observed in resistant tomatoes (23). Up to now, genetic analyses and QTL mapping in tomato considered only the wilting percentage, resulting from both the restriction of bacterial invasion and the tolerance to invasion. Analogies in the

Table 4. Independence test between quantitative resistance to bacterial wilt (mean AUDPC value over the 2 years) and resistance to the nematode Meloidogyne spp., to Potato virus Y (PVY), and to Tobacco mosaic virus (TMV) in the doubled haploid (DH) progeny of pepper ${ }^{\mathrm{a}}$

\begin{tabular}{|c|c|c|c|c|c|c|}
\hline & \multicolumn{2}{|c|}{ Meloidogyne spp. } & \multicolumn{2}{|c|}{ PVY } & \multicolumn{2}{|c|}{ TMV } \\
\hline & Resistant & Susceptible & Resistant & Susceptible & Resistant & Susceptible \\
\hline No. of DH lines & 50 & 29 & 24 & 29 & 28 & 24 \\
\hline Mean AUDPC & 4.12 & 2.85 & 2.41 & 3.48 & 3.91 & 1.90 \\
\hline Variance & 7.10 & 3.99 & 3.71 & 6.83 & 5.61 & 3.80 \\
\hline Student $t$ value ${ }^{\mathrm{b}}$ & \multicolumn{2}{|c|}{$2.40(P=0.02)$} & \multicolumn{2}{|c|}{$1.72(P=0.09)$} & \multicolumn{2}{|c|}{$3.36(P=0.001)$} \\
\hline
\end{tabular}

a Reaction of DH lines to the nematode Meloidogyne spp., PVY, and TMV were previously characterized $(6,7,8,27)$

${ }^{\mathrm{b}}$ Student $t$ values and probabilities were computed for bilateral mean comparison of samples with different variances.

genetics as well as in the expression of resistance in pepper and tomato offer motivation to look further for synteny between these two solanaceous crops for bacterial wilt resistance, and molecular markers of tomato resistance QTLs should be checked for their association with resistant phenotypes in the pepper doubled haploid progeny.

\section{ACKNOWLEDGMENTS}

We thank P. Prior for characterization of bacteria phylotype and Cindy Morris for helpful criticisms and review of the manuscript, H. Poitout, F. Sapotille, and P. B. Marival for technical assistance, and the experimental staff of INRA-Domaine de Duclos for field experimentation.

\section{LITERATURE CITED}

1. Abdullah, H., and Rahman, M. A. 1998. Multiplication of Ralstonia solanacearum in Capsicum annuum. Pages 309-315 in: Bacterial Wilt Disease, Molecular and Ecological Aspects. P. Prior, C. Allen, and J. Elphinstone, eds. Springer-Verlag, Berlin, Heidelberg, New York.

2. Ahmed, E. A., Daubèze, A. M., Lafortune, D., Depestre, T., Nono-Womdim, R., Duranton, C., Berke, T., Gaddagimath, N. B., Nemouchi, G., Phaly, T., and Palloix, A. 2001. Constructing multiresistant genotypes of sweet pepper for cultivation in the tropics. XIth EUCARPIA Meeting on Genetics and Breeding of Capsicum and Eggplant, Antalya, Turkey, 2001/04/09-13, 293-297.

3. Danesh, D., Aarons, S., McGill, G. E., and Young, N. D. 1994. Genetic dissection of oligogenic resistance to bacterial wilt in tomato. Mol. Plant-Microbe Interact. 7:464-471.

4. Darasse, A., Trigalet, A., and Prior, P. 1998 Correlation of aggressiveness with genomic variation in Ralstonia solanacearum Race 1. Pages 89-98 in: Bacterial Wilt Disease, Molecular and Ecological Aspects. P. Prior, C. Allen, and J. Elphinstone, eds. Springer-Verlag, Berlin, Heidelberg, New York.

5. Daubèze, A. M., Hennart, J. W., and Palloix, A. 1995. Resistance to Leveillula taurica in pepper (Capsicum annuum) is oligogenically controlled and stable in mediterranean regions. Plant Breed. 114:327-332.

6. Daubèze, A. M., Palloix, A., and Pochard, E. 1990. Resistance of androgenetic autodiploid lines of pepper to Phytophthora capsici and Tobacco Mosaic Virus under high temperature. Capsicum News1. 8/9:47-48.

7. Djian-Caporalino, C., Pijarovsky, L., Fazari, A., Samson, M., Gaveau, L., Lefebvre, V., Caranta, A., Palloix, A., and Abad, P. 2001. High resolution genetic mapping of the pepper (Capsicum annuum L.) resistance loci $\mathrm{Me} 3$ and $\mathrm{Me} 4$ conferring heat-stable resistance to root knot nematodes (Meloidogyne spp). Theor. Appl. Genet. 103:592-600.

8. Djian-Caporalino, C., Pijarovsky, L., Januel, A., Lefebvre, V., Phaly, T., Palloix, A., Dalmasso, A., and Abad, P. 1999. Spectrum of resistance to root knot nematodes (Meloidogyne spp.) in sweet pepper (Capsicum annuum L.) and inheritance of heat-stable resistance in the PM687 line derived from PI 322719. Theor. Appl. Genet. 99:496-502.

9. Fegan, M., and Prior, P. Bacterial Wilt Disease and the Ralstonia solanacearum Species Complex. C. Allen, P. Prior, and C. Hayward, eds. American Phytopathological Society, St. Paul, MN. In press.

10. Gao, G., Qu, D. Y., Lian, Y., Jin, L. P., and Feng, L. X. 2000. Identification of molecular markers linked with resistance to bacterial wilt (Ralstonia solanacearum) in diploid potato. Acta Hortic. Sinica 27:37-41. 
11. Grimault, V., and Prior, P. 1994. Invasiveness of Pseudomonas solanacearum in tomato, eggplant and pepper: A comparative study. Eur. J. Plant Pathol. 100:259-267.

12. Hayward, A. C. 1964. Characteristics of Pseudomonas solanacearum. J. Appl. Bacteriol. 27:265-277.

13. Hayward, A. C. 1991. Biology and epidemiology of bacterial wilt caused by Pseudomonas solanacearum. Annu. Rev. Phytopathol. 29:6587.

14. Ihaka, R., and Gentleman, R. 1996. R: A language for data analysis and graphics. J. Computational Graphical Stat. 5:299-314.

15. Lefebvre, V., Palloix, A., Caranta, C., and Pochard, E. 1995. Construction of an intraspecific integrated linkage map of pepper using molecular markers and doubled haploid progenies. Genome 38:112-121.

16. Lefebvre, V., Pflieger, S., Thabuis, A., Caranta, C., Blattes, A., Chauvet, J. C., Daubèze, A. M., and Palloix, A. 2002. Towards the saturation of the pepper linkage map by alignment of three intraspecific maps including known-function genes. Genome 45:839-854.

17. Lindhout, P. 2002. The perspectives of polygenic resistance in breeding for durable disease resistance. Euphytica 124:217-226.

18. Lopes, C. A., and Quezado-Soares, A. M 1995. Stability of resistance in the potato Achat to bacterial wilt. Hortic. Bras. 13:57-58.

19. Mangin, B., Thoquet, P., Olivier, J., and Grimsley, N. H. 1999. Temporal and multiple quantitative trait loci analyses of resistance to bacterial wilt in tomato permit the resolution of linked loci. Genetics 151:1165-1172.

20. Mather, K., and Jinks, J. L. 1982. Biometrical Genetics. 3rd ed. Chapman and Hall, London.

21. Matsunaga, H., and Monma, S. 1995. Varietal differences in resistance to bacterial wilt in related species of Capsicum annuum. Capsicum Eggplant Newsl. 14:60-61.
22. Michelmore, R. 1995. Molecular approaches to manipulation of disease resistance genes. Annu. Rev. Phytopathol. 15:393-427.

23. Nakaho, K., Hibino, H., and Miyagawa, H. 2000. Possible mechanisms limiting movement of Ralstonia solanacearum in resistant tomato tissues. J. Phytopathol. 148:181-190.

24. Nishi, T., Tajima, T., Nogushi, S., Ajisaka, H., and Nagishi, H. 2003. Identification of DNA markers of tobacco linked to bacterial wilt resistance. Theor. Appl. Genet. 106:765-770.

25. Peter, K. V., Goth, R. W., and Webb, R. E. 1984. Indian hot peppers as new sources of resistance to bacterial wilt, Phytophthora root rot and root rot nematodes. Hortscience 19:277-278.

26. Pflieger, S., Lefebvre, V., Caranta, C., Blattes, A., Goffinet, P., and Palloix, A. 1999. Disease resistance gene analogs as candidates for QTLs involved in pepper/pathogen interactions. Genome 42:1100-1110.

27. Pochard, E., Palloix; A., and Daubèze, A. M. 1986. The use of androgenetic autodiploid lines for the analysis of complex resistance systems in the pepper. VI Eucarpia Meeting on Genetics and Breeding on Capsicum and Eggplant, Saragozza, Spain, 1986/10/21-24, 105-109.

28. Prior, P., and Steva, H. 1990. Characteristics of strains of Pseudomonas solanacearum from the French West Indies. Plant Dis. 74:13-17.

29. Prior, P., Steva, H., and Cadet, P. 1990. Aggressiveness of strains of Pseudomonas solanacearum from the French West Indies (Martinique and Guadeloupe) on tomato. Plant Dis. 74:962-965.

30. Quesado-Soares, A. M., and Lopes, C. A. 1995. Stability of the resistance to bacterial wilt of the sweet pepper 'MC-4' challenged with strains of Pseudomonas solanacearum. Fitopathol. Bras. 20:638-641.

31. Rahman, M. A., Abullah, H., and Vanhaecke, M. 1999. Histopathology of susceptible and resistant Capsicum annuum cultivars infected with Ralstonia solanacearum. J. Phytopathol. 147:129-140.

32. Rowe, P. R., Sequeira, L., and Gonzalez, L. C. 1972. Additionnal genes for resistance to Pseudomonas solanacearum in Solanum phureja. Phytopathology 62:1093-1094.

33. Snape, J. W., Wright, A. J., and Simpson, E. 1984. Methods for estimating the gene numbers for quantitative characters using doubled haploid lines. Theor. Appl. Genet. 67:143-148.

34. Thoquet, P., Olivier, J., Sperisen, C., Rogowsky, P., Prior, P., Anaïs, G., Mangin, B. Bazin, B., Nazer, R., and Grimsley, N. 1996. Polygenic resistance of tomato plants to bacterial wilt in the French West Indies. Mol. PlantMicrobe Interact. 9:837-842.

35. Van der Wolf, J. M., Bonants, P. J. M., Smith, J. J., Hagenaar, M., Nijhuis, E., Van Beckhoven, R. C. M., Saddler, G. S., Trigalet, E., and Feuillade, R. 1998. Genetic diversity of Ralstonia solanacearum race 3 in Western Europe determined by AFLP, RC-PFGE and Rep-PCR Pages 44-49 in: Bacterial Wilt Disease, Molecular and Ecological Aspects. P. Prior, C. Allen, and J. Elphinstone, eds. Springer-Verlag, Berlin, Heidelberg, New York.

36. Wang, J.-F., Olivier, J., Thoquet, P., Mangin, B., Sauviac, L., and Grimsley, N. H. 2000. Resistance to tomato line Hawaii7996 to Ralstonia solanacearum PSS4 in Taiwan is controlled mainly by a major strain specific locus. Mol. Plant-Microbe Interact. 13:6-13.

37. Yoon, J. Y., Green, S. K., Tschanz, A. T., Tsou, S. C. S., and Chang, L. C. 1989. Pepper improvement for the tropics: Problems and the AVRDC approach. Pages 86-98 in: Tomato and Pepper production in the Tropics, Proc. Int. Sympos. Integrated Management Practices, Tainan, Taiwan 21-26 March 1988. S. K Green, T. D. Griggs, and B. T. McLean, eds. AVRDC Publications, AVRDC Shanhua, Tainan. 